\title{
Intraairway Thermal Profiles during Exercise and Hyperventilation in Normal Man
}

\author{
E. R. McFadden, Jr., and B. M. Pichurko \\ With the technical assistance of Brian Sullivan and Steven Pardee \\ Shipley Institute of Medicine and the Departments of Medicine of the Brigham and Women's Hospital and Harvard Medical School, \\ Boston, Massachusetts 02115, and The Asthma and Allergic Disease Center and Departments of Medicine, \\ University Hospitals and Case Western Reserve University School of Medicine, Cleveland, Ohio 44106
}

\begin{abstract}
When large volumes of air are inhaled at rapid rates of ventilation, substantial segments of the tracheobronchial tree become involved in the conditioning process and the inspirate does not reach body conditions of temperature and humidity until it passes well into the peripheral bronchi. To determine if the manner in which ventilation is elevated is an important factor in producing this response, we measured the temperature of the airstream at six points in the tracheobronchial tree from the pharynx to the subsegmental bronchi during $5 \mathrm{~min}$ of exercise and voluntary hyperventilation in seven normal subjects while they inhaled frigid air. Minute ventilation and respiratory frequency were recorded at minute intervals and intrathoracic temperatures were measured continuously. With both forms of hyperpnea, airway temperature fell dramatically, and there were no significant differences between exercise and hyperventilation. These results demonstrate that the thermal events that occur within the lung during short, moderately intense degrees of exercise can be readily simulated by voluntary hyperventilation when ventilation and inspired air conditions are matched. Our data also indicate that this form of exercise does not result in an increase in airstream temperature and raise the possibility that the bronchial blood supply may be determined by the local thermal needs of the airways to recover heat and water independent of, at least moderate, increases in cardiac output.
\end{abstract}

\section{Introduction}

Data derived from direct measurements within the tracheobronchial tree demonstrate that when minute ventilation is voluntarily increased, the temperature of the airstream within the intrathoracic airways of normal subjects falls in a predictable fashion, and at the point at which the air reaches body conditions of temperature and humidity, moves deep into the periphery of the lung $(1,2)$. In these studies, the subjects voluntarily performed hyperventilation which resulted in very little metabolic or cardiac stress, and so it is not known if the findings are applicable to other situations, such as exercise, in which major increases in cardiac output and heat production regularly occur. To provide data on this point, as well as to gain more insight into the factors controlling the transfer of heat and water, we have recorded the

Address correspondence to Dr. McFadden, Asthma and Allergic Disease Center, University Hospitals, Case Western Reserve University School of Medicine, 2074 Abington Rd., Cleveland, $\mathrm{OH} 44106$. 1985

Received for publication 22 January 1985 and in revised form 6 May

J. Clin. Invest.

(C) The American Society for Clinical Investigation, Inc.

0021-9738/85/09/1007/04 \$1.00

Volume 76, September 1985, 1007-1010 thermal profiles that develop within the intrathoracic airways in normal subjects during both forms of hyperpnea. Our observations form the basis of this report.

\section{Methods}

Seven normal volunteers (five males and two females) with a mean age of $29 \pm 2$ (SEM) yr served as our subjects. After informed consent was obtained, the nose and throat of each subject were anesthetized with $2 \%$ lidocaine and a fiberoptic bronchoscope was inserted through the nasopharynx into a subsegmental bronchus of the anterior segment of the right lower lobe. During the passage of the endoscope, the distances from the tip of the nose to the major anatomic landmarks were recorded. As in a previous study, a specially designed flexible thermal probe containing multiple small thermistors was inserted into a subsegmental bronchus (2). The distance from the nose to the proximal end of the probe was recorded and the bronchoscope was removed. The probe was withdrawn in small recorded increments until the most distal thermistor showed fluctuations in temperature with a deep breath, confirming its location in an unobstructed bronchus. By knowing the length of the probe, the distance the tip was inserted, and the location of each anatomic landmark relative to the tip of the nose, the position of each thermistor within the tracheobronchial tree could be determined. Minimal anesthesia was used in the airways during the positioning of the probe and, once the probe was inserted, it was well tolerated. No additional anesthesia was given or needed in any instance after the probe was in place. The stability of the position of the probe was continuously verified as in earlier experiments (2).

The technical features of the probe have been reported previously (2). In brief, the thermistors were $250 \mu \mathrm{m}$ in diameter, evenly spaced at $4.3 \mathrm{~cm}$ from each other, and arranged in a spiral pattern over the distal $30.2 \mathrm{~cm}$ of the probe. Each thermistor was electrically and physically isolated from its neighbor, and the output of each was sampled approximately 8 times per second with an analog to Digital converter and a PDP-11 computer (Digital Equipment Corp., Marlboro, MA). The 63\% response time of the probe assembly was $0.25 \mathrm{~s}$ in stirred water.

After the probe was secured in position, each subject performed 5 min of exhausting leg work on a cycle ergometer (mean workload $=1071 \pm 96$ kilopondmeter) while inhaling frigid air through a heat exchanger (3-5). The water content of the inspired air was $<0.05 \mathrm{mg} \mathrm{H}_{2} \mathrm{O} /$ liter, which for the purposes of this study was considered to be zero. During the performance of the work load, minute ventilation $\left(\dot{V}_{E}\right)^{1}$ and respiratory frequency $(f)$ were recorded at minute intervals by collecting expired gas in a Tissot spirometer. The temperature within the airways was recorded continuously throughout the exercise task with a Digital computer (2)

Upon completion of the workload the subjects rested 30 min with the probe in place and then simulated the $\dot{V}_{E}$ and respiratory pattern of each minute of exercise by performing isocapnic hyperventilation using previously reported techniques (6-9). As in former studies, expired air was directed away from the heat exchanger into a reservoir balloon which was being constantly evacuated at a known rate through a calibrated rotameter. The subjects were coached to respire so as to keep the balloon filled, and in so doing their $\dot{V}_{E}$ could be set to any desired value. End-

1. Abbreviations used in this paper: $\dot{\mathrm{V}}_{\mathrm{E}}$, minute ventilation; $\mathrm{T}_{\text {insp }}$, temperature during inspiration. 
tidal carbon dioxide concentrations were monitored with a Beckman LB-2 analyzer (Beckman Instruments, Inc., Fullerton, CA) and sufficient carbon dioxide was added to the inspiratory port of the exchanger to maintain end-tidal carbon dioxide at eucapnic levels. Respiratory frequency was matched to that recorded during exercise on a minute by minute basis with a metronome. The temperature of the heat exchanger for each subject during hyperventilation was identical to that used in the exercise experiments. Also, as with exercise, the temperature of the airstream within the tracheobronchial tree was recorded continuously.

The data were analyzed by paired $t$ tests, one factor analysis of variance, and analysis of covariance.

\section{Results}

The ventilatory pattern observed during cycle ergometry is shown in Fig. 1. During exercise, $\dot{V}_{E}$ rose from $19.4 \pm 3.7$ liter/min to a peak value of $71.6 \pm 8 \mathrm{liter} / \mathrm{min}$ at the end of the fifth minute. Over the same period, $f$ rose from $14.4 \pm 1.6$ to $35.1 \pm 2.5$ breaths/ min. A steady state was reached in that there were no significant differences between the values for the fourth and fifth minute for either variable.

Because of the critical dependence of the results of this investigation on the accuracy with which the hyperpnea of exercise could be matched voluntarily, the validity of the hyperventilation technique was assessed by having the subjects sustain a range of target $\dot{V}_{E}$ for 4 to $5 \mathrm{~min}$ while their expired volumes were recorded directly with a dry gas meter. These studies were conducted independently of the main investigation. The data are shown in Fig. 2. In these experiments the measured $\dot{V}_{E}$ exceeded the target $\dot{\mathrm{V}}_{\mathrm{E}}$ which the subjects were to have achieved by a mean value of 0.9 liter $/ \mathrm{min}$; the $P$ value was not significant.

The thermal profiles during the first $4 \mathrm{~min}$ of each form of hyperpnea are shown in Fig. 3. The average temperature of the inspired air was $-17.8 \pm 1.8^{\circ} \mathrm{C}$ with exercise and $-17.3 \pm 1.9^{\circ} \mathrm{C}$ with hyperventilation (the $P$ value was not significant). Airstream temperatures were measured in the supraglottic region, the trachea, the bronchus intermedius, and beyond the orifice of the anterior segmental bronchus. Before exercise, the temperatures during inspiration $\left(\mathrm{T}_{\text {insp }}\right)$ at $5 \mathrm{~cm}$ above the glottis averaged $29.9 \pm 0.8^{\circ} \mathrm{C}$, and as the air moved toward the periphery, $\mathrm{T}_{\text {insp }}$ progressively rose reaching $35.7 \pm 0.7^{\circ} \mathrm{C}$ at the most distal position. As $\dot{V}_{E}$ increased with work, $T_{\text {insp }}$ continuously fell at each point. By the fourth minute, $T_{\text {insp }}$ in the posterior pharynx and anterior segment of the right lower lobe had decreased to $23 \pm 1.0$ and $30.7 \pm 1.0^{\circ} \mathrm{C}$, respectively.
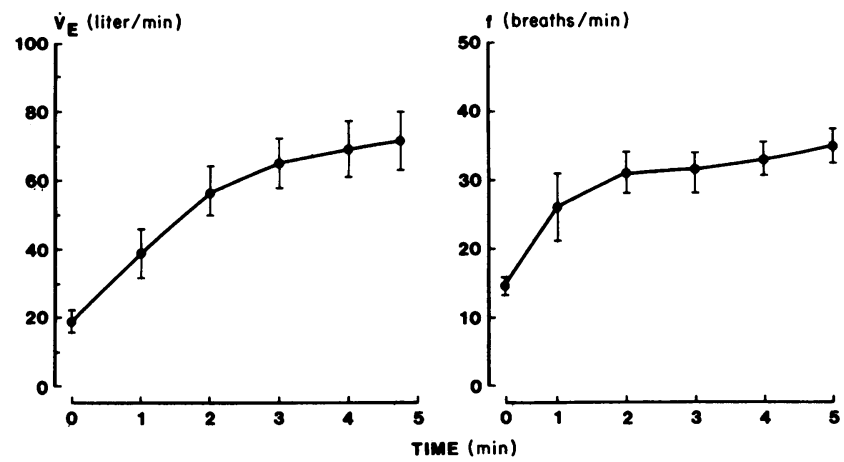

Figure $1 . \dot{\mathrm{V}}_{\mathrm{E}}$ and $f$ as a function of time during exercise. The data points are mean values and the brackets represent 1 SEM.

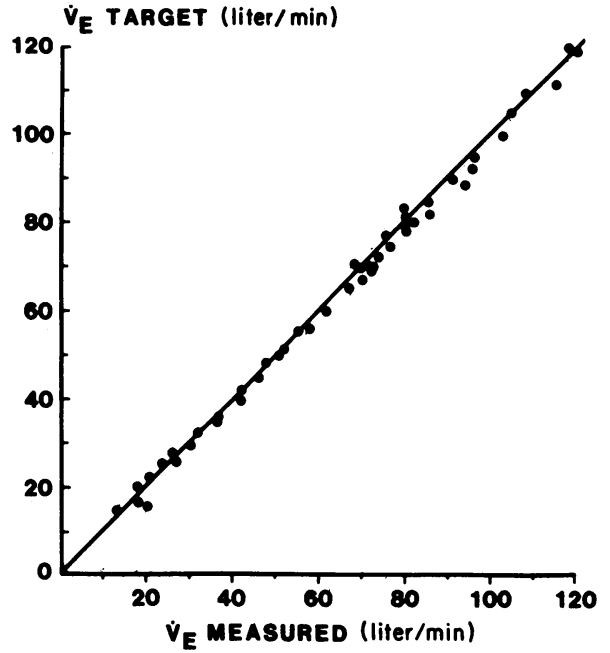

Figure 2. Validation of the isocapnic hyperventilation technique. $\dot{\mathbf{V}}_{\mathbf{E}}$ target is the minute ventilation the subject is to sustain by matching the emptying rate of a target balloon that is being evacuated via a calibrated rotameter and vacuum source. $\dot{\mathrm{V}}_{\mathrm{E}}$ measured is the absolute minute ventilation of the subject during this period as measured with an inline dry gas meter.

A similar phenomenon was found both qualitatively and quantitatively with hyperventilation. The temperature in the airways in the rest period before exercise was $0.7 \pm 0.4^{\circ} \mathrm{C}$ higher than during the corresponding period in the hyperventilation period. This difference was significant at the $P=0.01$ level by analysis of covariance and was derived mainly from the vari-

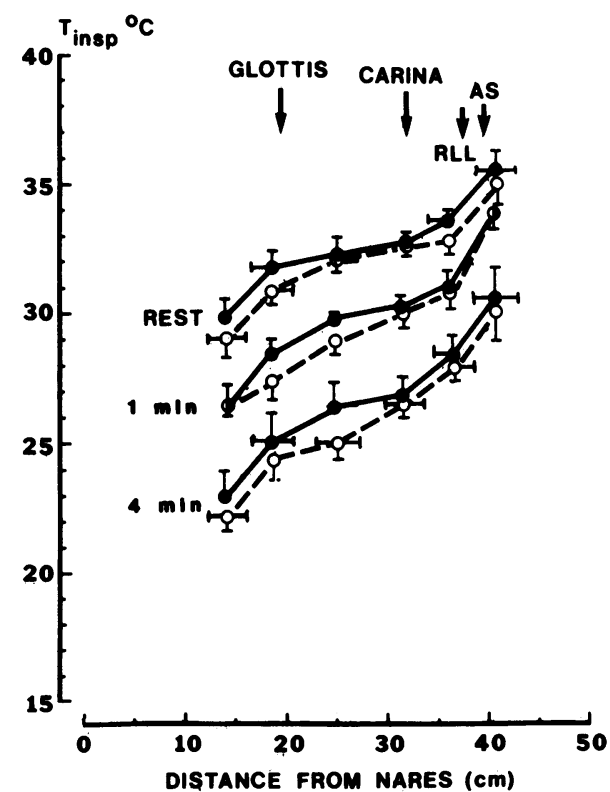

Figure 3. Comparison of the mean $\mathrm{T}_{\text {insp }}$ of the air stream at various points in the tracheobronchial tree as a function of the distance from the nares at rest and during the first and fourth minutes of exercise and isocapnic hyperventilation. The arrows refer to the location of the anatomic landmarks. RLL, right lower lobe; AS, anterior segmental bronchus. The data points are mean values and the brackets represent $1 \mathrm{SE}$. The values for minute ventilation and frequency for each time period are shown in Fig. 1. _- -, exercise; -- ०--, hyperventilation. 
ability recorded at thermistor 2 . By the first minute, the thermal profiles with both stimuli were statistically similar and after that time period, neither paired point by point comparisons, nor analysis of variance, revealed any differences between the two forms of hyperpnea. The similarity between exercise and hyperventilation is most clearly seen when the data from the final minute are contrasted (Fig. 4).

The reproducibility of the temperature measurements during exercise and hyperventilation are shown in Fig. 5. With both forms of hyperpnea, airstream temperatures achieved a steady state and the data from the fourth and fifth minutes are superimposable.

\section{Discussion}

The results of the present study confirm previous investigations regarding the relationship between $\dot{\mathrm{V}}_{E}$ and the temperatures within the intrathoracic airways $(1,2)$. For a given set of inspired air conditions, other than those believed to exist in the alveoli, increasing $\dot{V}_{E}$ results in a quantifiable reduction in the temperature of the air throughout a considerable segment of the tracheobronchial tree. Our data also demonstrate that the mechanism by which hyperpnea is produced is immaterial. According to standard tables, the work load that we used would have resulted in an oxygen consumption of $\sim 3$ liter/min and a cardiac output of 20 liter or more (10). Given the fact that airway temperatures progressively fell as cardiac output rose (Fig. 2), it is apparent that simply increasing blood flow through the lungs via the pulmonary circulation does not, of itself, change the thermal profile within the airways. Further, the increased metabolic demands of this level of exercise does not produce different respiratory thermal effects as compared with hyperventilation and its minimal cardiac and metabolic consequences. Hence, the intraairway thermal events associated with moderately severe work can be readily simulated by isocapnic hyperventilation when $\dot{V}_{E}$ and inspired air conditions are matched.

\section{FINAL MINUTE}

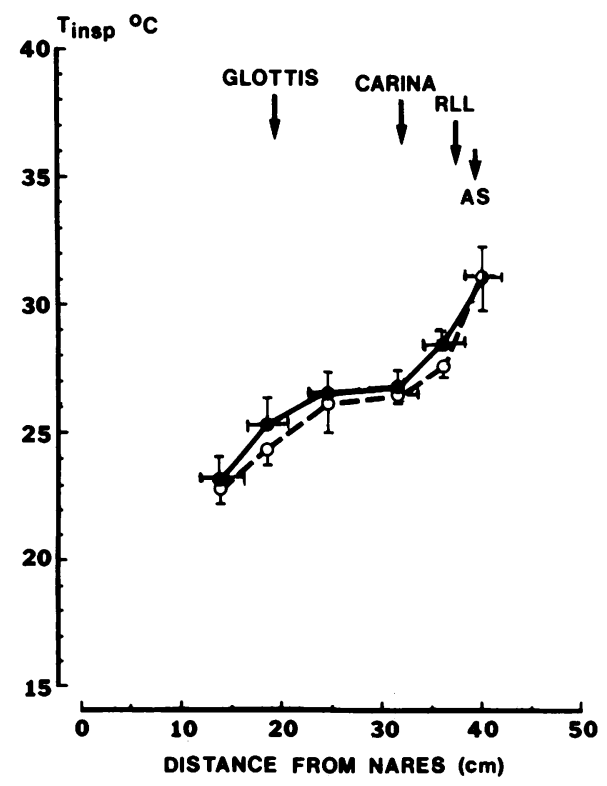

Figure 4. Comparison of $\mathrm{T}_{\text {insp }}$ in the final minute of exercise and hyperventilation. The format is identical to Fig. 3. - $\bullet-$, exercise; - - O--, hyperventilation.

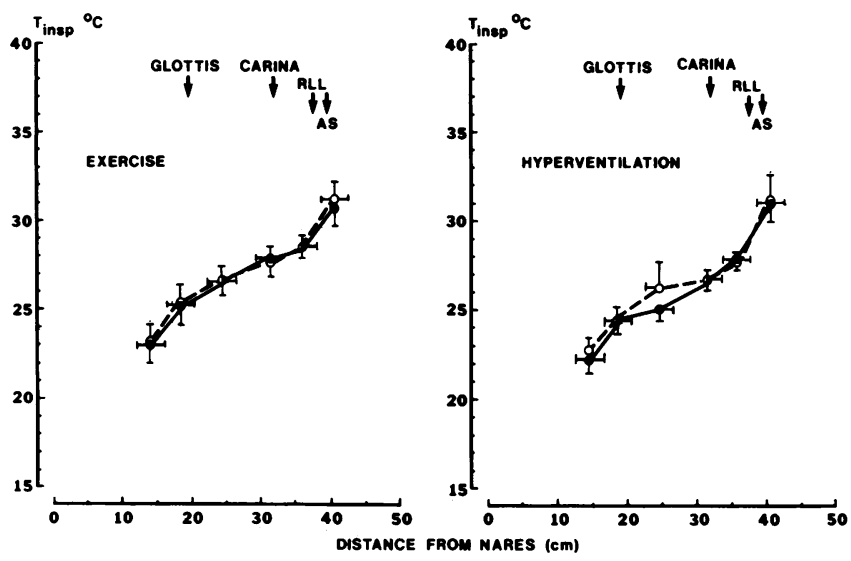

Figure 5. Demonstration of steady states and reproducibility of $\mathbf{T}_{\text {insp }}$ of the airstream with exercise and hyperventilation. The format is identical to Figs. 3 and $4 .-\bullet-$, fourth minute; -- -- , fifth minute.

Our findings emphasize the relative inefficiency of the respiratory tract of man as a means of regulating body temperature, under most circumstances, and highlight the differences in the thermal functions of the airways of humans and other species (11-13). In man, unlike the dog (13), the physiology of the respiratory tract is geared toward minimizing heat and water losses to the environment. To achieve this end, it appears that the bronchial vascular bed constricts when exposed to falling temperatures to keep the airways as cool as possible in order to facilitate recovery of the thermal energy that was used to warm and humidify the air during inspiration.

It has long been appreciated that either an increase in $\dot{V}_{E}$ or a decrease in the temperature of the air being inhaled result in a reduction of the temperature of the exhaled air and so its water content, and that the combination of hyperpnea and a frigid inspirate produce the greatest effect $(2,14-16)$. Direct measurements of intraairway temperatures have extended these earlier observations by demonstrating that recovery begins well in the periphery of the lung and continues progressively as the expirate moves toward the mouth (2). This could only occur if the temperature of the mucosa was lower than that of the air stream.

The available data indicate that the degree of cooling of the tracheobronchial tree that develops with the combination of high $\dot{\mathrm{V}}_{\mathrm{E}}$ and frigid air in man can be substantial. With these conditions, as shown in the present study and others (2), tracheal airstream temperatures in the mid-twenties are regular occurrences, and a sufficient reduction in tracheal wall temperature develops to cool the retrotracheal esophagus $(5,8,17)$. Most recently we have been able to demonstrate that when airstream temperatures fall with hyperpnea the temperature of the airway wall falls concomitantly to levels only a few degrees higher of that of the air (Ingenito, E., and E. R. McFadden, unpublished observations). It is difficult to see how any of this could occur if blood at body temperature were bathing the airways.

When the results of the present study are viewed in the above context, they suggest that during periods of high $\dot{\mathrm{V}}_{E}$ the bronchial blood supply may actually be determined, in part, by the local need to recover heat and water independent of increases in cardiac output. If the bronchial vessels had dilated in response to the increase in flow during exercise, airstream temperatures would have been expected to have risen as the result of the increase in heat being brought to the mucosa and submucosa $(1$, 
13); yet, the response was just the opposite. Temperatures fell as they did with hyperventilation.

Although our results strongly suggest that exercise and hyperventilation produce equivalent intrapulmonary thermal effects over the range that these challenges are employed clinically, they may not do so under all circumstances. If we had imposed a greater absolute work load, or duration, and/or had interfered with evaporative losses from the skin during exercise, it is probable that, as core temperature rose, the lungs would have been called on to eliminate the excess heat (12). In this situation it is likely that the intraairway thermal profiles would have differed markedly between exercise and isocapnic hyperventilation. The limits of exertion at which the two stimuli can be disassociated has not yet been defined.

We do not believe that our results were unduly influenced by technical features such as the response time of our probe and the anesthesia used to prepare the subjects for probe placement. Because the response time of the probe was relatively slow, it is probable that we underestimated the true breath by breath excursions that occurred. However, since we had our subjects reproduce the respiratory pattern recorded during exercise when they hyperventilated voluntarily, both forms of hyperpnea were underestimated to the same extent.

With respect to airway anesthesia, we know from previous work that lidocaine and analogues increase local temperature presumably by dilating the mucosal vessels (1). If this factor had a major effect in our study, it would actually have biased against our findings and not contributed to them. Since exercise was always performed first to determine the subjects $\dot{V}_{E}$ and respiratory patterns, airstream temperatures would have been expected to have been higher with this challenge then with hyperventilation and not equal. Anesthetic effects, however, undoubtedly account for why the temperatures tended to be slightly greater at the start of the exercise study than they were later when the hyperventilation experiments commenced.

In summary, in normal subjects, it appears that the intrapulmonic thermal profiles that develop during moderately intense exercise can be accurately simulated by voluntary hyperventilation. The range over which this similitude is operational, however, remains to be determined. Nonetheless, it is anticipated that the application of the techniques used in the present study to patients with airway disease may provide valuable insights as to how individuals with such conditions heat and humidify inspired air and develop thermally induced airway obstruction.

\section{Acknowledgments}

This work was supported in part by grant HL17873 and Specialized Center of Research grant HL19170 from the National Heart, Lung, and Blood Institute.

\section{References}

1. McFadden, E. R., Jr., D. M. Denison, J. R. Waller, B. Assoufi, A. Peacock, and T. Sopwith. 1982. Direct recordings of the temperatures in the tracheobronchial tree in normal man. J. Clin. Invest. 69:700-705.

2. McFadden, E. R., Jr., B. M. Pichurko, K. F. Bowman, E. Ingenito, S. Burnes, N. Dowling, and J. Solway. 1985. Thermal mapping of the airways in man. J. Appl. Physiol. (Respir. Environ. Exercise Physiol). 58:564-570.

3. Strauss, R. H., E. R. McFadden, Jr., R. H. Ingram, Jr., E. C. Deal, Jr., and J. J. Jaeger. 1978. Influence of heat and humidity on the airway obstruction induced by exercise in asthma. J. Clin. Invest. 61:443-440.

4. Deal, E. C., Jr., E. R. McFadden, Jr., R. H. Ingram, Jr., R. H. Strauss, and J. J. Jaeger. 1979. Role of respiratory heat exchange in the production of exercise induced asthma. J. Appl. Physiol. (Respir. Environ. Exercise Physiol.). 46:467-475.

5. Deal, E. C., Jr., E. R. McFadden, Jr., R. H. Ingram, Jr., and J. J. Jaeger. 1979. Esophageal temperature during exercise in asthmatic and non-asthmatic subjects. J. Appl. Physiol. (Respir. Environ. Exercise Physiol.). 46:484-490.

6. Deal, E. C., Jr., E. R. McFadden, Jr., R. H. Ingram, Jr., and J. J. Jaeger. 1979. Hyperpnea and heat flux: initial reaction sequence in exercise induced asthma. J. Appl. Physiol. (Respir. Environ. Exercise Physiol.). 46:476-483.

7. Deal, E. C., Jr., E. R. McFadden, Jr., R. H. Ingram, Jr., F. J. Breslin, and J. J. Jaeger. 1980. Airway responsiveness to cold air and hyperpnea in normal subjects and in those with hay fever and asthma. Am. Rev. Respir. Dis. 121:621-628.

8. Breslin, F. J., E. R. McFadden, Jr., R. H. Ingram, Jr., and E. C. Deal, Jr. 1980. Effects of atropine on respiratory heat loss in asthma. $J$. Appl. Physiol. (Respir. Environ. Exercise Physiol.). 48:619-623.

9. O'Cain, C. F., N. B. Dowling, A. S. Slutsky, M. J. Hensley, K. P. Strohl, E. R. McFadden, Jr., and R. H. Ingram, Jr. 1980. Airway effects of respiratory heat loss in normal subjects. J. Appl. Physiol. (Respir. Environ. Exercise Physiol.). 49:875-880.

10. Astrand, P. O., and K. Rodahl. 1970. Work Physiology. McGrawHill, Inc., New York. 158, 209.

11. Taylor, C. R. 1977. Exercise and environmental loads, different mechanisms for solving different problems? Int. Rev. Physiol. (II. Environ. Physiol.) 15:119-146.

12. Mitchell, J. W., E. R. Nadel, and J. A. J. Stolwijk. 1972. Respiratory weight losses during exercise. J. Appl. Physiol. 32:474-476.

13. Baile, E. M., R. W. Dahlby, B. R. Wiggs, and P. D. Paré. 1985. Role of tracheal and bronchial circulation in respiratory heat exchange. J. Appl. Physiol. (Respir. Environ. Exercise Physiol.). 58:217-222.

14. Webb, P. 1951. Air temperatures in respiratory tracts of resting subjects in cold. J. Appl. Physiol. 4:378-382.

15. Cole, P. 1953. Further observations on the conditioning of respiratory air. J. Laryngal. Otol. 67:669-681.

16. Cole, P. 1954. Recordings of respiratory air temperature. J. Laryngol. Otol. 68:295-307.

17. Cranston, W. I., J. Gerbrandy, and E. S. Snell. 1954. Oral, rectal and esophageal temperatures and some factors affecting them in man. J. Physiol. (Lond.). 126:347-358. 